\title{
Expression of Oryzacystatin I and II in Alfalfa Increases Resistance to the Root-Lesion Nematode
}

\author{
Deborah A. Samac and Ann C. Smigocki
}

First author: U.S. Department of Agriculture-Agricultural Research Service (USDA-ARS)-Plant Science Research Unit, University of Minnesota, Department of Plant Pathology, St. Paul 55108; and second author USDA-ARS-Plant Molecular Pathology Laboratory, 10300 Baltimore Ave., Beltsville, MD 20705. Accepted for publication 30 January 2003.

\begin{abstract}
Samac, D. A., and Smigocki, A. C. 2003. Expression of oryzacystatin I and II in alfalfa increases resistance to the root-lesion nematode. Phytopathology 93:799-804.

Digestive cysteine proteinases have been isolated from plant-parasitic nematodes as well as coleopteran and hemipteran insects. Phytocystatins, inhibitors of cysteine proteinases, are found in a number of plants where they may play a role in defense against pathogens and pests. The cDNAs of the phytocystatins from rice, oryzacystatin I (OC-I) and oryzacystatin II (OC-II), were expressed in alfalfa (Medicago sativa) plants under the control of the potato protease inhibitor II (PinII) promoter and the plants

alfalfa to determine the pattern of gene expression from this promoter. Constitutive GUS expression was observed in leaf and root vascular tissue, and in some plants, expression was observed in leaf mesophyll cells. Mechanical wounding of leaves increased GUS expression approximately twofold over $24 \mathrm{~h}$. Inoculation with root-lesion nematodes resulted in localized GUS expression. Populations of root-lesion nematodes in alfalfa roots from one line containing the PinII::OC-I transgene and one line containing the PinII::OC-II transgene were reduced 29 and $32 \%$, respectively, compared with a transgenic control line. These results suggest that oryzacystatins have the potential to confer increased resistance to the root-lesion nematode in alfalfa.
\end{abstract} were evaluated for resistance to the root-lesion nematode (Pratylenchus penetrans). A PinII- $\beta$-glucuronidase (GUS) gene was introduced into

Oryzacystatin I (OC-I) and oryzacystatin II (OC-II) are cysteine proteinase inhibitors from rice in the phytocystatin family of proteinase inhibitors $(2,19)$. Phytocystatins are low-molecular-weight proteins that have been isolated from a range of plants including seeds of soybean (23), corn (1), cowpea (12), and chestnut (27), subepidermal cells of potato tubers (39), and tomato leaves overexpressing the wound-induced signal molecule prosystemin (16). OC-I and OC-II are both found in ripening rice seeds, but they share only $55 \%$ amino acid identity with each other and have distinct inhibitory activities; OC-I has greater activity against papain, whereas OC-II has greater activity against cathepsin (19). Endogenous substrates have been identified from plants, indicating that phytocystatins have a role in regulation of proteinases during seed development and germination $(3,13)$ and as modulators of programmed cell death activated during pathogen attack and oxidative stress (30). Phytocystatins may also function in protection of seeds because they are potent inhibitors of exogenous proteinases, such as the digestive enzymes of insect pests $(21,27)$ and fungal pathogens (26).

Cysteine proteinase activity has been observed in the intestines of the sedentary nematodes Heterodera glycines (22) and $H$. schachtii (37), and expression of cysteine proteinase inhibitors in transgenic plants has been shown to provide effective control of root-knot, cyst, and reniform nematodes. A modified rice cystatin,

Corresponding author: D. A. Samac; E-mail address: dasamac@umn.edu

Mention of a trademark, proprietary product, or vendor does not constitute a guarantee or warranty of the product by the USDA, and does not imply its approval to the exclusion of other products and vendors that might also be suitable.

Publication no. P-2003-0422-01R

This article is in the public domain and not copyrightable. It may be freely reprinted with customary crediting of the source. The American Phytopathological Society, 2003.
Additional keywords: cystatin, lucerene, proteinase inhibitor.
$\mathrm{OC}-\mathrm{I} \Delta \mathrm{D} 86$, inhibits cysteine proteinase activity of papain (34) and the cathepsin L-like proteinase of $H$. glycines (36) in vitro. Cysteine proteinase activity in the intestines of $H$. glycines is inhibited by purified OC-I $\Delta$ D86 (22) and female $H$. schachtii feeding on plants expressing OC-I $\Delta \mathrm{D} 86$ show loss of intestinal cysteine proteinase activity (37). Constitutive expression of OC-I $\triangle \mathrm{D} 86$ reduced the size of Globodera pallida females feeding on tomato roots $(4,34)$, reduced the size and egg production of $H$. schachtii and Meloidogyne incognita females in Arabidopsis spp. (37), reduced egg production of Meloidogyne incognita in rice (38) and size of females in tomato (4), and reduced egg laying and size of Rotylenchus reniformis females in Arabidopsis spp. (35).

The goal of this study was to investigate the effect of OC-I and OC-II expression in alfalfa (Medicago sativa) on the root-lesion nematode (Pratylenchus penetrans). The root-lesion nematode is a migratory endoparasite with a broad host range that can cause economic levels of damage to many crop species (11). Surveys have determined that damaging population levels of root-lesion nematodes occur in many agricultural areas in the midwestern and eastern United States (32). Although genetic resistance to many sedentary nematodes, such as the root-knot and cyst-forming nematodes, has been introduced into adapted plant cultivars, developing cultivars with resistance to migratory nematodes has been more difficult. Genes for anti-feedants such as proteinase inhibitors in combination with genetic resistance and/or cultural practices could reduce nematode populations and plant damage (17). In order to minimize exposure of nontarget organisms to proteinase inhibitors, a promoter that is expressed predominantly in roots or is induced by nematode activity is desired. Several nematode-induced gene promoters have been reported $(15,24,25)$ but their expression has not been tested in alfalfa. We investigated the activity of the potato protease inhibitor II (PinII) promoter (28) in alfalfa using a PinII- $\beta$-glucuronidase (GUS) transgene and tested the effect of OC-I and OC-II cDNAs under the control PinII promoter on root-lesion nematode populations in alfalfa roots. 


\section{MATERIALS AND METHODS}

Binary plasmid vectors. The pGT130 plant transformation vector contains the Escherichia coli GUS uidA gene fused to the PinII gene promoter as previously described in Snyder et al. (29). The pGV-OCI and pGV-OCII plasmids carry the rice OC-I (2) and OC-II (19) cDNAs, respectively, fused to the PinII promoter (28). The OC-I and OC-II gene constructs were subcloned as HindIII fragments into the pGPTV-KAN binary vector (7). All binary vectors carry the neomycin phosphotransferase II (nptII) gene fused to the nopaline synthase gene (nos) promoter for selection of transormed plant cells. Vectors were mobilized into Agrobacterium tumefaciens LBA4404 by triparental mating (8).

Plant transformation and plant culture. Alfalfa leaf explants from a highly regenerable clone of Regen-SY (9) were cocultured with Agrobacterium tumefaciens and somatic embryos were produced essentially as described by Austin et al. (5). After establishing plants in soil, DNA was extracted from young leaves using the Puregene Kit (Gentra Systems, Minneapolis) according to the manufacturer's instructions. Plants were tested by polymerase chain reaction (PCR) for the presence of nptII using specific primers (NPTII forward 5'-GCTATGACTGGGCACAACAGAC$3^{\prime}$ and NPTII reverse 5'-CGTCAAGAAGGCGATAGAAGG-3') and subsequently for the presence of coding regions for GUS (PinII forward 5'-GGCTCCTCCGTCCAATTATA-3' and GUS reverse 5'-TCACCATTGGCCACCACCTGCC-3'), OC-I (PinII forward and OCI reverse $5^{\prime}$-ATCGACAGGCTTGAACTCCT-3'), or OC-II (PinII forward and OCII reverse 5'-GGTGGCGTCGTCGAGGGG-3'). Reactions consisted of $1 \mu \mathrm{g}$ of DNA in a 50- $\mu$ l reaction with $2.0 \mathrm{mM} \mathrm{MgCl} 2,50$ pmol each primer, $0.25 \mathrm{mM}$ each dNTP, and 1 unit of Taq DNA polymerase (Promega, Madison, WI). Reactions were carried out for 30 cycles of $94^{\circ} \mathrm{C}$ for $30 \mathrm{~s}$, $58^{\circ} \mathrm{C}$ for $1 \mathrm{~min}$, and $72^{\circ} \mathrm{C}$ for $1 \mathrm{~min}$.

Due to the obligate outcrossing nature of alfalfa, all experiments were carried out using vegetative cuttings of primary transformants. Nodal stem sections were rooted in sterile moist vermiculite for approximately 14 days, transferred to a mix of sand and soil $(1: 1, \mathrm{vol} / \mathrm{vol})$ in $3.8-\times 21-\mathrm{cm}$ plastic cone-tainers (Stuewe \& Sons, Corvallis, OR), and fertilized monthly with soluble 10:20:10 (N:P:K) fertilizer.

$\beta$-Glucuronidase assays. Expression patterns of the PinII-GUS transgene were assessed by infiltrating fresh tissue pieces with a 1 $\mathrm{mg} / \mathrm{ml}$ solution of 5-bromo-4-chloro-3-indoyl- $\beta$-D-glucuronic acid (X-gluc) at $37^{\circ} \mathrm{C}$ for $15 \mathrm{~h}$ as described previously (31) and subsequently removing chlorophyll with $70 \%$ ethanol. Induction of the promoter by nematodes was tested by inoculating plants 1 week after transplanting with either 300 root-lesion nematodes obtained from axenic cultures on sterile corn roots (6) or with approximately 10 egg masses of the root-knot nematode (Meloidogyne hapla) extracted from carrot root galls. Nematodes suspended in water were introduced into the soil around plant roots with a $5-\mathrm{ml}$ pipette. Roots were stained for GUS activity 9 days and 7 weeks after inoculation. Following X-gluc staining, roots were treated with acid fuchsin for visualization of nematodes (10). Induction of the promoter by wounding was carried out by crushing leaflets across the midvein in three places with a pair of hemostats. For each plant, two samples of three leaflets were harvested at 0 (nonwounded), 3, 6, and $24 \mathrm{~h}$ after wounding. Samples were frozen in liquid nitrogen and stored at $-80^{\circ} \mathrm{C}$ until assayed. Leaves were ground in GUS extraction buffer (10 $\mu \mathrm{l}$ per mg of tissue) (14) and diluted 1:10 with extraction buffer. Samples of $5 \mu \mathrm{l}$ were assayed in triplicate in extraction buffer with $5 \mu \mathrm{l}$ of $50 \mathrm{mM}$ 4-methylumbelliferyl- $\beta$-D-glucuronic acid (MUG) in $250-\mu$ l reactions. Fluorescence of the 4-methylumbelliferone (4-MU) produced was measured over $30 \mathrm{~min}$ at $37^{\circ} \mathrm{C}$ with a microplate fluorescence reader (BioTek FL600; BioTek Instruments, Winooski, VT) equipped with a $360 / 40 \mathrm{~nm}$ excitation filter and $450 / 50 \mathrm{~nm}$ detection filter. Fluorescence units of 4-MU standards in extraction buffer were used to calibrate the plate reader. Protein concenttion was determined by a protein assay (Bio-Rad Laboratories, Hercules, CA) with bovine serum albumin as the standard.

RNA extraction and reverse transcription-PCR. Total RNA was extracted from root tips (lower $2 \mathrm{~cm}$ ) of vegetative cuttings grown in vermiculite for 2 weeks. Roots were ground in liquid nitrogen with a mortar and pestle and then extracted with $1 \mathrm{ml}$ per $0.1 \mathrm{~g}$ of Trizol reagent (Life Technologies, Rockville, MD) as specified by the manufacturer. RNA in $50 \mu \mathrm{l}$ of RNase-free water was treated with 1 unit of RQ1 RNase-free DNase (Promega, Madison, WI) for $1 \mathrm{~h}$ at $37^{\circ} \mathrm{C}$ according to the manufacturer's directions. RNA was purified using RNeasy columns (Qiagen, Valencia, CA) and eluted in $100 \mu \mathrm{l}$ of RNase-free water. Reverse transcription (RT)-PCR was performed by the Access RT-PCR System (Promega) according to the manufacturer's instructions with $60 \mathrm{pg}$ of RQ1-treated RNA with the primers OCI forward (5'-GACGGAGGGCCGGTGCTT-3') and OCI reverse or OCII forward (5'-GAGGAGGCGCAGAGCCAC-3') and OCII reverse. An annealing temperature of $55^{\circ} \mathrm{C}$ was used for OC-I primers and $53^{\circ} \mathrm{C}$ with OC-II primers. The predicted products from amplification with OC-I primers or OC-II primers were 282 and $312 \mathrm{bp}$, respectively. A $20-\mu \mathrm{l}$ aliquot of each completed reaction was electrophoresed through $1 \%$ agarose gels in $1 \times$ TAE buffer $(40 \mathrm{mM}$ Tris-acetate and $1 \mathrm{mM}$ EDTA), gels were stained with ethidium bromide, and bands were visualized under UV light.

Root-lesion nematode assays. Nematodes were grown in axenic culture on sterile corn roots as described previously (6). Vegetative cuttings of transgenic alfalfa lines and nontransformed Regen-SY were planted into a mixture of heat-treated sand and soil $(1: 1, \mathrm{vol} / \mathrm{vol})$ in $3.8-\times 21-\mathrm{cm}$ plastic cone-tainers and placed in a growth chamber at $25^{\circ} \mathrm{C}$ with a 16-h photoperiod, light intensity of approximately $600 \mu \mathrm{mol} \mathrm{m} \mathrm{s}^{-2} \mathrm{~s}^{-1}$, and $50 \%$ relative humidity. The experiment consisted of nine plants from each line in a completely randomized design. Plants were inoculated twice, 3 and 4 weeks after planting, with 150 root-lesion nematodes per plant by introducing a suspension of nematodes into the soil around plant roots with a 5-ml pipette. Foliage was clipped at 8,12 , and 16 weeks after planting, dried at $55^{\circ} \mathrm{C}$ for 7 days, and weighed to determine forage yield. To determine nematode populations, roots were removed from soil 16 weeks after planting. Fibrous roots were removed from washed root systems, clipped into approximately $1-\mathrm{cm}$ pieces, and placed in $25-\times 100-\mathrm{mm}$ glass petri dishes containing $50 \mathrm{ml}$ of tap water. Plates were placed on an orbital platform at $25^{\circ} \mathrm{C}$ and shaken at $60 \mathrm{rpm}$. After 7 days, the water was decanted and the nematode suspension was stored at $4^{\circ} \mathrm{C}$ until aliquots were counted with a stereozoom dissecting microscope. Roots were dried at $55^{\circ} \mathrm{C}$ for 7 days and weighed. The comparison among different alfalfa lines was made by analysis of variance for a completely randomized design using the general model procedure in SAS (SAS Institute, Cary, NC). Data analysis for nematodes per gram dry root weight was performed following $\log _{10}$ transformation. The least significant difference test was used for mean separation when the overall $F$ test was significant at $P<0.05$. For ease of interpretation and discussion, results for log-transformed variables were detransformed back to the original units.

\section{RESULTS}

Constitutive and wound-induced GUS expression from the PinII promoter. A total of 27 plants containing the PinII::GUS transgene (pGT130) were identified by PCR. Three distinct patterns of X-gluc staining were observed in these plants. Approximately one-third of the plants $(n=11)$ had GUS activity in leaf and root vascular tissue and root tips (Fig. 1A). In eight plants GUS expression was observed in leaf mesophyll (Fig. 1B), in leaf and root vascular tissue, and root tips. Light blue staining in a portion of the leaf in Figure 1B is due to limited infiltration of X- 
gluc into mesophyll tissues. Eight plants that were positive by PCR for the presence of the transgene had no detectable constitutive GUS activity by X-gluc staining.

The response of the PinII promoter was compared during infection by the root-lesion nematode, which causes extensive damage to root cells during migration through the root, and Meloidogyne hapla, which causes minimal tissue damage. Infection by the root-lesion nematode induced localized GUS expression in the root cortex, whereas infection by Meloidogyne hapla caused little change in GUS expression. In plants with constitutive GUS activity in root vascular tissue and root tips, GUS activity was observed 9 days postinoculation with root-lesion nematodes in individual root cortical cells (Fig. 1C). Nematodes were observed close to GUS-positive areas after staining roots with acid fuchsin (Fig. 1C). Seven weeks after inoculation, GUS activity in root-lesion nematode-inoculated roots was similar to that seen at 9 days after inoculation. In plants inoculated with the root-knot nematode, GUS activity was observed in vascular tissue of roots 9 days after inoculation with some staining associated with enlarged areas near the root tip, most likely the cells of developing root galls (Fig. 1D). Seven weeks after inoculation with root-knot nematodes, GUS staining was observed in root vascular tissue with more intense staining in vascular tissue near galls and weak blue staining in cells surrounding the female nematode. Plants shown in Figure 1C and D had moderate GUS activity in root vascular tissue and root tips; blue staining was reduced by fixation and acid fuchsin staining. In three of five plants tested that had no detectable constitutive GUS expression, GUS staining was observed in root vascular tissue 7 weeks after inoculation with either root-lesion or root-knot nematodes but GUS staining was not observed near nematodes.

Wound-inducible expression of the PinII::GUS gene in leaves was evaluated with a fluorescent assay of GUS activity and histochemical staining. Two lines with no detectable GUS activity by X-gluc staining (pGT130-1 and -2), four lines with expression in leaf vascular tissues (pGT130-17, -20, -23, and -27), and three lines with expression in vascular tissue and mesophyll (pGT130-6,
-11, and -19) were tested. The experiment was carried out twice with similar results. Figure 2 shows the results from one experiment. Activity in plants with only vascular activity before wounding ranged from 205 to 263 pmol 4-MU per min per mg of protein (Fig. 2B). Activities in these plants did not change appreciably by $6 \mathrm{~h}$ after wounding. By $24 \mathrm{~h}$ after wounding, activities increased approximately 1.3 - to 2.3-fold. A similar trend, a 1.1- to 2.0-fold increase over $24 \mathrm{~h}$, was observed in plants with GUS activity in mesophyll and vascular tissue although GUS activities before wounding were higher in these plants (Fig. 2C). No GUS activity was detected in line pGT130-1 or -2 at any time (Fig. 2A). Histochemical staining of leaves from the same lines containing the PinII::GUS transgene $24 \mathrm{~h}$ after wounding did not reveal any changes in the pattern of GUS expression; there was not a marked increase in staining near wounds or any other part of the leaflet compared with unwounded leaves.

Detection of transcripts in roots and leaves. Eight plants with the PinII::OC-I construct and 26 plants with the PinII::OC-II construct were identified by PCR. Detection of transgene transcripts in root tips and leaves in a subset of transformed lines was done by RT-PCR. Of the six lines tested containing the PinII::OC-I transgene, four lines (OCI-1, $-3,-4$, and -5) were positive for the predicted RT-PCR product of $282 \mathrm{bp}$ in leaves and root tips (Table $1)$. In line OCI-2 the transcript was detected only in leaves, and line OCI- 8 was positive for the transcript in roots only. Of the 17 lines containing the PinII::OC-II transgene that were tested, three had the predicted 312-bp product in roots and leaves (OCII-7, -17, and -18), in five lines the transcript was detected only in roots, in two lines the transcript was detected in only leaves, and in seven lines the transcript was not detected (OCII-1, -12, -13, -15, -24, -26 , and -27).

Resistance to the root-lesion nematode. Plants from a subset of transgenic lines were challenged with $P$. penetrans based on the detection of transgene transcripts. Six lines that were positive for transgene transcripts in roots (OCI-1, -3, -4, and -5; OCII-7 and -17), three lines without detectable transgene transcripts in roots (OCI-2; OCII-1 and -15), four lines containing the PinII::GUS
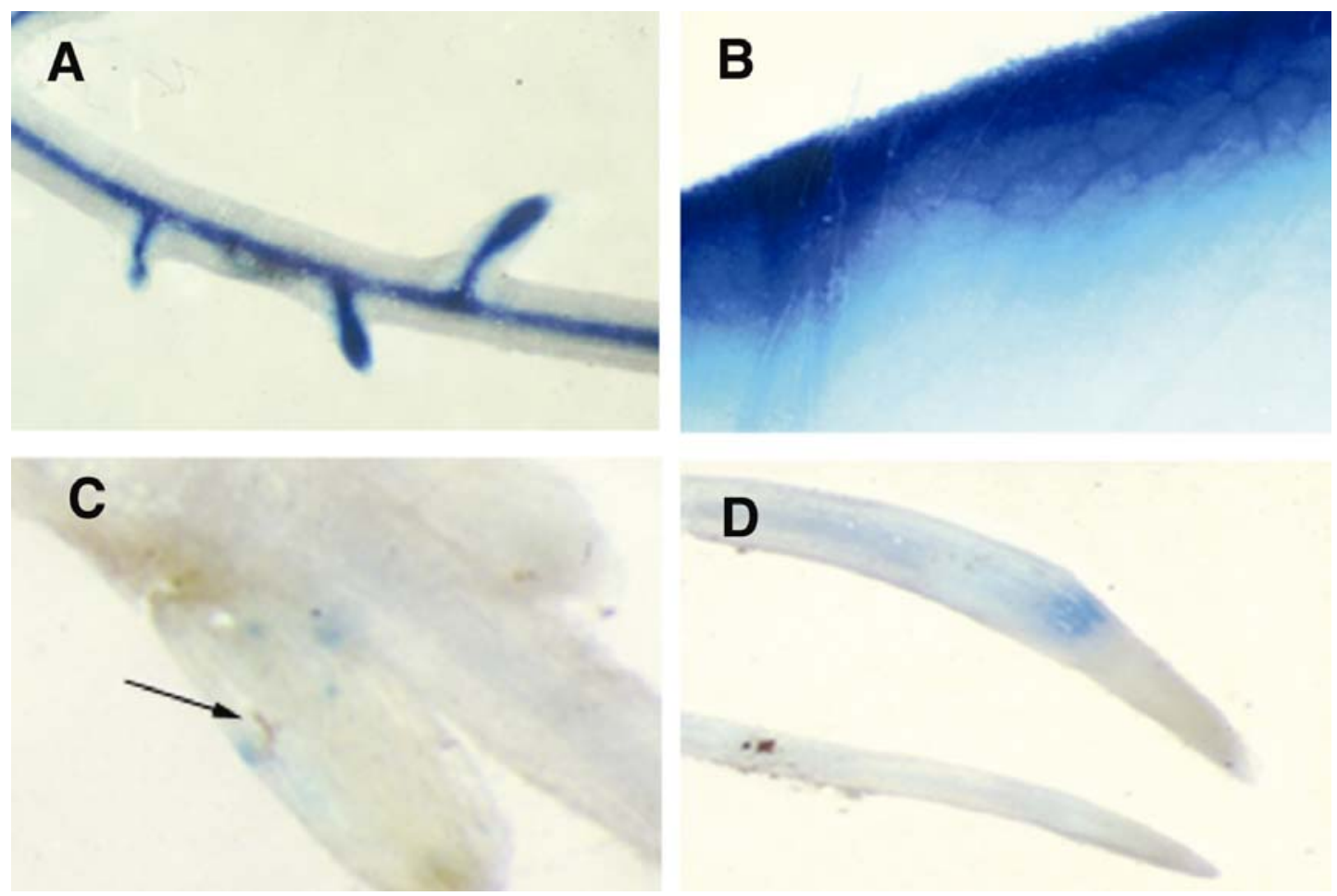

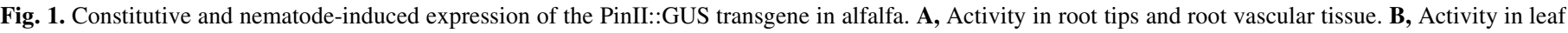

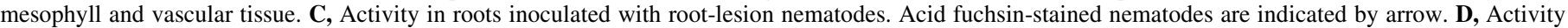
in a root-knot nematode infected root (top) 9 days after inoculation and control noninoculated root (bottom). 


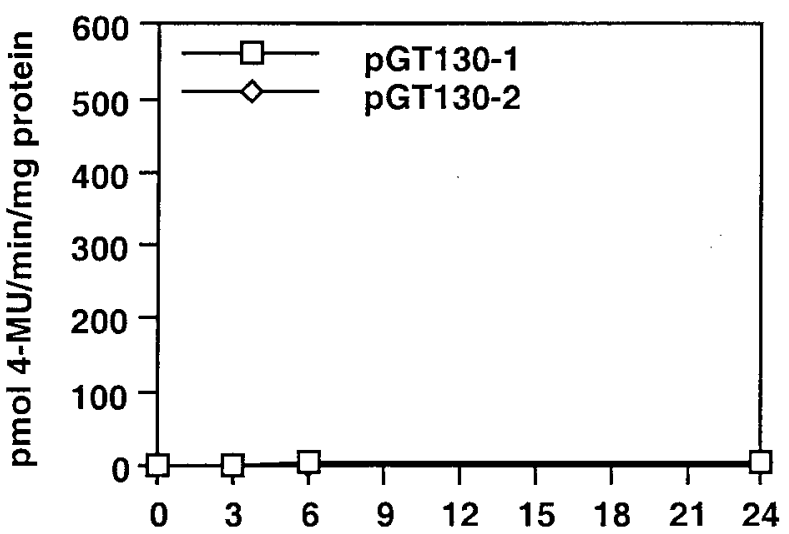

B

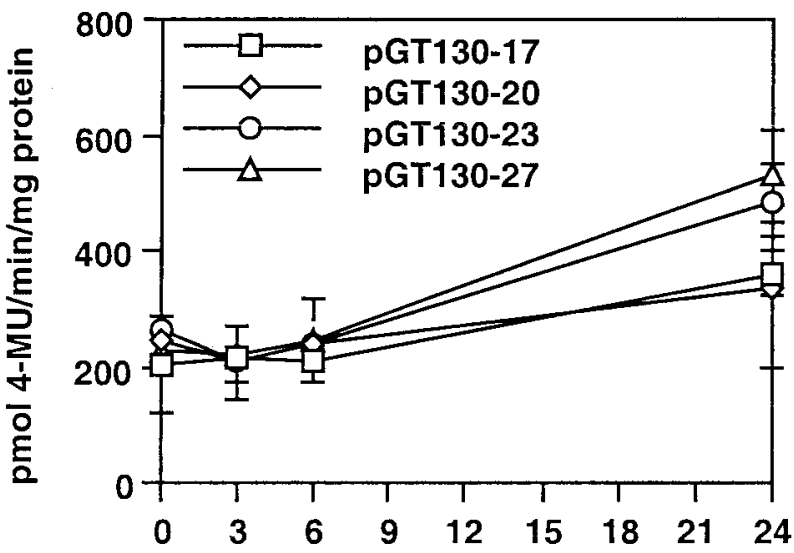

C

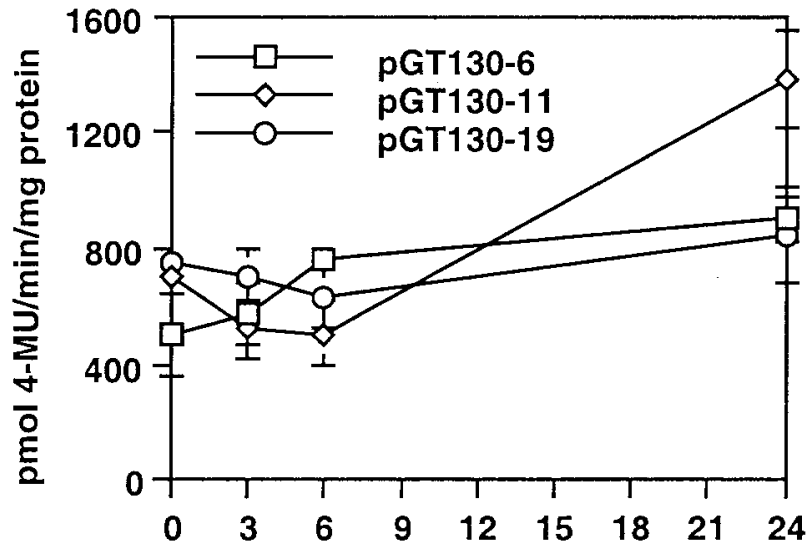

\section{Hours after wounding}

Fig. 2. Wound-induced $\beta$-glucuronidase (GUS) activity in alfalfa leaves. A, Plant lines with no GUS activity detected by staining. B, Pant lines with activity limited to vascular tissue. C, Plant lines with expression in leaf mesophyll and vascular tissue.

construct (pGT130-2, -6, -11, and -27), and nontransformed control plants (Regen-SY) were tested. Total forage yield, root dry weight, and populations of nematodes in roots of these plants were compared. The experiment was carried out twice with similar results. Total forage yield and root dry weight did not differ significantly among plant lines (Table 1). Nematode populations were similar in nontransformed Regen-SY plants and plants with the PinII::GUS construct. A significant reduction $(P<0.05)$ in the mean number of nematodes per gram of dry root was found in plants from one line with the PinII::OC-I construct (OCI-4) and one line with the PinII::OC-II construct (OCII-7) compared with nontransformed Regen-SY (Table 1). Lower mean nematode populations were observed in other lines with the PinII::OC-I and PinII::OC-II constructs compared with Regen-SY but differences were not significant due to the large variation in nematode populations. Decreased populations of the root-lesion nematode were associated with the presence of the transgene transcript. Nematode populations in transgenic lines in which the transgenes were not detected in roots, OCI-2 and OCII- 1 and -15 , were similar to populations in Regen-SY.

\section{DISCUSSION}

Several gene promoters are responsive to root-knot and cyst nematodes $(15,24,25)$, but the response of these promoters to migratory nematodes has not been tested. The root-lesion nematode causes considerable damage to roots as it moves and feeds resulting in characteristic reddish brown necrotic lesions. A number of defense response genes are induced by the root-lesion nematode in alfalfa (6) including a proteinase inhibitor with similarity to the PinII gene (G. D. Baldridge and D. A. Samac, unpublished data). The PinII promoter was chosen to direct expression of the OC-I and OC-II cDNAs in alfalfa on the assumption that expression would be induced by activity of the root-lesion nematodes and other mechanical wounding. Confining expression to plant parts under attack would minimize exposure of nontarget organisms, should conserve metabolic energy of the plants, and minimize physiological effects of the transgenes on plant metabolism.

Analysis of alfalfa plants containing the PinII::GUS transgene showed that the expression pattern of the PinII promoter in alfalfa is distinctly different from the patterns of expression observed in potato and rice. In potato plants, constitutive expression of a PinII::GUS transgene was observed in stolons and tubers with no detectable expression in roots, stems, or leaves (18). However, if the leaves are wounded, GUS expression may increase up to 62fold. GUS activity occurs throughout the wounded leaf and is associated with vascular tissue in systemically induced leaves (18). In rice plants containing a PinII::GUS transgene, GUS expression in unwounded leaf tissues is undetectable (41). Upon wounding, GUS activity occurs throughout the wounded leaf with the most intense GUS staining occurring in the leaf vascular tissue. In the wounded leaf, GUS activity increases up to ninefold $24 \mathrm{~h}$ after wounding. Nonwounded roots show GUS expression in the root tip, whereas wounded roots show GUS expression in whole root tissues (41). In contrast, alfalfa plants had constitutive expression of the PinII::GUS gene in leaves and roots (Fig. 1). In some plants expression in leaves was limited to vascular tissue, and in other plants constitutive expression occurred in mesophyll cells. In alfalfa, wounding leaves had only a small effect on GUS expression; wounding increased GUS activity in leaves approximately twofold over $24 \mathrm{~h}$ and no change in the pattern of expression was observed. This indicates that in alfalfa the PinII gene promoter is not a strong wound-inducible promoter. Transcripts from the PinII::OC-I and PinII::OC-II transgenes were detected in roots and leaves of alfalfa plants by RT-PCR. However, northern blots for detection of transcripts in roots and leaves resulted in weak probe hybridization (data not shown), providing additional support for a low level of PinII promoter activity in alfalfa plants. In addition, the amounts of OC-I or OC-II protein in wounded or nonwounded alfalfa leaves were below the level of detection by protein-immunoblots (data not shown). Because immunologically detectable amounts of OC-I have been produced in transgenic plants using the Cauliflower mosaic virus (CaMV) 35S promoter $(20,21,37,38)$, our results suggest that the low amount of inhibitor is due to weak promoter activity rather than transcript or protein instability in alfalfa. Nonetheless, recent sequencing of a genomic clone of OC-I revealed the presence of a signal peptide sequence that is not present in the cDNA clone used in this work (40). Presence of the signal peptide might increase transcription and transcript stability in transgenic plants. 


\begin{tabular}{|c|c|c|c|c|c|}
\hline \multirow[b]{2}{*}{ Plant line } & \multicolumn{2}{|c|}{ Detection of transcript ${ }^{\mathrm{x}}$} & \multirow[b]{2}{*}{ Forage yield $(\mathrm{g})^{\mathrm{y}}$} & \multirow[b]{2}{*}{ Root dry weight (g) } & \multirow[b]{2}{*}{ P. penetrans (g dry root $)^{\mathrm{z}}$} \\
\hline & Root & Leaf & & & \\
\hline Regen-SY & - & - & 2.15 & 0.118 & $24,257 \mathrm{ab}$ \\
\hline pGT130-2 & - & - & 2.24 & 0.115 & $16,646 \mathrm{ab}$ \\
\hline pGT130-6 & - & - & 1.94 & 0.139 & $17,128 \mathrm{ab}$ \\
\hline pGT130-11 & - & - & 2.19 & 0.190 & $10,551 \mathrm{a}-\mathrm{c}$ \\
\hline pGT130-27 & - & - & 2.18 & 0.138 & $15,126 \mathrm{ab}$ \\
\hline OCI-1 & + & + & 2.44 & 0.229 & $7,136 \mathrm{~b}-\mathrm{d}$ \\
\hline OCI-2 & - & + & 2.34 & 0.135 & $22,346 \mathrm{a}$ \\
\hline OCI-3 & + & + & 2.79 & 0.253 & $5,910 \mathrm{~b}-\mathrm{d}$ \\
\hline OCI-4 & + & + & 2.66 & 0.534 & $4,362 \mathrm{~d}$ \\
\hline OCI-5 & + & + & 2.71 & 0.411 & $6,132 \mathrm{~b}-\mathrm{d}$ \\
\hline OCII-1 & - & - & 2.28 & 0.187 & $17,258 \mathrm{a}-\mathrm{c}$ \\
\hline OCII-15 & - & - & 2.40 & 0.137 & $9,923 \mathrm{a}-\mathrm{c}$ \\
\hline OCII-7 & + & + & 2.49 & 0.250 & $4,827 \mathrm{~cd}$ \\
\hline OCII-17 & + & + & 2.87 & 0.248 & $7,303 \mathrm{~b}-\mathrm{d}$ \\
\hline
\end{tabular}

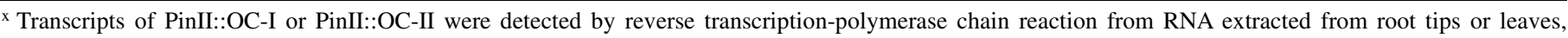
respectively.

${ }^{y}$ Forage yield (total from three harvests) and root dry weights not significantly different among plant lines.

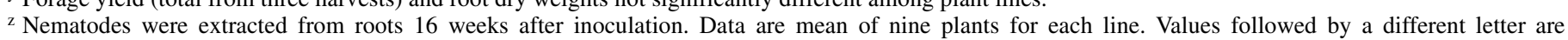
significantly different at $P<0.05$.

Interestingly, GUS expression in root cortical cells was associated with infection by root-lesion nematodes in lines containing the PinII::GUS gene (Fig. 1C). Localized gene expression suggests that nematode activity, probably localized tissue damage, induced transgene expression. Infection and feeding by Meloidogyne hapla occurs with minimal damage to host tissues and is reflected in the pattern of GUS expression in infected PinII::GUS plants. Constitutive GUS expression occurred in vascular tissue of uninfected plants and plants infected with Meloidogyne hapla; expression was not induced in the developing galls or in mature galls. Thus, the low activity of this promoter in roots and leaves limits its utility in alfalfa for controlling genes for broad-spectrum pest and pathogen resistance.

The digestive enzymes of the root-lesion nematode have not been characterized; however, cysteine proteinases are present in a wide variety of nematodes (33) and are likely present in $P$. penetrans. A significant decrease $(P<0.05)$ in the population of rootlesion nematodes was observed in roots of one line containing the PinII::OC-I construct with a detectable constitutive transgene transcript and one line showing constitutive expression of the PinII::OC-II transcript compared with nontransformed control plants (Table 1). Populations of root-lesion nematodes in OCI-4 and OCII-7 were reduced 29 to $32 \%$, respectively, compared with populations in pGT130-12, the control line with the lowest population of root-lesion nematodes. This result suggests that the proteinase inhibitors produced constitutively by root cells had a negative effect on root-lesion nematode development. Although the PinII promoter was induced by the root-lesion nematode, induced expression of the cystatins may have minimal impact on nematode populations if the proteinase inhibitors must be ingested to have an effect. Root-lesion nematodes were observed adjacent to cortical cells with GUS activity (Fig. 1C) but did not appear to be feeding from these cells. In previous reports, expression of OC$\mathrm{I} \Delta 86$ under the control of the CaMV $35 \mathrm{~S}$ promoter, a strong constitutive promoter, resulted in the modified cystatin accumulating up to $0.4 \%$ of the total soluble protein in Arabidopsis plants (37). In these plants, normal development of $H$. schachtii and Meloidogyne incognita was prevented, the cystatin was detected in females feeding on the plants, and intestinal cysteine proteinase activity was lost (37). Lower amounts of the cystatin also affect nematode development. In rice plants in which OC-I $\Delta 86$ accumulation was less than $0.2 \%$ of total soluble protein, a $55 \%$ reduction in the number of eggs produced by Meloidogyne incognita occurred (38). In alfalfa plants, a promoter with stronger expression in root tissues would likely enhance the amount of inhibitor made and increase the level of plant resistance to the root-lesion nematode.

\section{ACKNOWLEDGMENTS}

This paper is a joint contribution from the USDA-Agricultural Research Service and the Minnesota Agricultural Experiment Station. We thank D. MacDonald for supplying root-knot nematodes and $\mathrm{M}$. Dornbush, S. Lutz, K. P. Nguyen, and M. Tesfaye for technical assistance.

\section{LITERATURE CITED}

1. Abe, M., Abe, K., Kuroda, M., and Arai, S. 1992. Corn kernel cysteine proteinase inhibitor as a novel cystatin superfamily member of plant origin: Molecular cloning and expression studies. Eur. J. Biochem. 209:933-937.

2. Abe, K., Emori, Y., Kondo, H., Suzuki, K., and Arai, S. 1987. Molecular cloning of a cysteine proteinase inhibitor of rice (oryzacystatin). J. Biol. Chem. 262:16793-16797.

3. Arai, S., Matsumoto, I., and Abe, K. 1998. Phytocystatins and their target enzymes: From biology to practical application. J. Food Biochem. 22:287-299.

4. Atkinson, H. J., Urwin, P. E., Clarke, M. C., and McPherson, M. J. 1996. Image analysis of the growth of Globodera pallida and Meloidogyne incognita on transgenic tomato roots expressing cystatins. J. Nematol. 28:209-215.

5. Austin, S., Bingham, E. T., Matthews, D. E., Shahan, M. N., Will, J., and Burgess, R. R. 1995. Production and field performance of transgenic alfalfa (Medicago sativa L.) expressing alpha-amylase and manganesedependent lignin peroxidase. Euphytica 85:381-393.

6. Baldridge, G. D., O’Neill, N. R., and Samac, D. A. 1998. Alfalfa (Medicago sativa L.) resistance to the root-lesion nematode, Pratylenchus penetrans: Defense-response gene mRNA and isoflavonoid phytoalexin levels in roots. Plant Mol. Biol. 38:999-1010.

7. Becker, D., Kemper, L., Schell, J., and Masterson, R. 1992. New plant binary vectors with selectable markers located proximal to the left TDNA border. Plant Mol. Biol. 20:1195-1197.

8. Bevan, M. 1984. Binary Agrobacterium vectors for plant transformation. Nucleic Acids Res. 12:8711-8720.

9. Bingham, E. T. 1991. Registration of alfalfa hybrid Regen-SY germplasm for tissue culture and transformation research. Crop Sci. 31:1098.

10. Byrd, D. W., Jr., Kirkpatrick, T., and Barker, R. K. 1983. An improved technique for clearing and staining plant tissues for detection of nematodes. J. Nematol. 15:142-143.

11. Corbett, D. C. M. 1973. Pratylenchus penetrans. No. 25 in: Descriptions of Plant-Parasitic Nematodes. Commonw. Inst. Helminthology, St. Albans, Herts., England.

12. Fernandes, K. V. S., Campos, F. A. P., Do Val, R. R., and Xavier-Filho, J. 1991. The expression of papain inhibitors during development of cowpea seeds. Plant Sci. 74:179-184.

13. Fujimaki, M., Abe, M., and Arai, S. 1977. Degradation of zein during germination of corn. Agric. Biol. Chem. 41:887-891.

14. Gallagher, S. R. 1992. Quantitation of GUS activity by fluorometry. Pages 47-59 in: GUS Protocols. S. R. Gallagher, ed. Academic Press, San Diego.

15. Hansen, E., Harper, G., McPherson, M. J., and Atkinson, H. J. 1996. Dif- 
ferential expression patterns of the wound-inducible transgene wunluidA in potato roots following infection with either cyst or root knot nematodes. Physiol. Mol. Plant Pathol. 48:161-170.

16. Jacinto, T., Fernandes, K. V. S., Machado, O. L. T., and Siqueira-Júnior, C. L. 1998. Leaves of transgenic tomato plants overexpressing prosystemin accumulate high levels of cystatin. Plant Sci. 138:35-42.

17. Jung, C., Cai, D., and Kleine, M. 1998. Engineering nematode resistance in crop species. Trends Plant Sci. 3:266-271.

18. Keil, M., Sánchez-Serrano, J., and Willmitzer, L. 1989. Both woundinducible and tuber-specific expression are mediated by the promoter of a single member of the potato proteinase inhibitor II gene family. EMBO J. 8:1323-1330.

19. Kondo, H., Abe, K., Nishimura, I., Watanabe, H., Emori, Y., and Arai, S. 1990. Two distinct cystatin species in rice seeds with different specificities against cysteine proteinases. J. Biol. Chem. 265:15832-15837.

20. Lecardonnel, A., Chauvin, L., Jouanin, L., Beaujean, A., Prévost, G., and Sangwan-Norreel, B. 1999. Effects of rice cystatin I expression in transgenic potato on Colorado potato beetle larvae. Plant Sci. 140:71-79.

21. Leplé, J. C., Bonadé-Bottino, M., Augustin, S., Pilate, G., Le-Tan, V. D., Delplanque, A., Cornu, D., and Jouanin, L. 1995. Toxicity to Chrysomela tremulae (Coleoptera: Chrysomelidae) of transgenic poplars expressing a cysteine proteinase inhibitor. Mol. Breed. 1:319-328.

22. Lilley, C. J., Urwin, P. E., McPerson, M. J., and Atkinson, H. J. 1996. Characterization of intestinally active proteinases of cyst-nematodes. Parasitology 113:415-424.

23. Misaka, T., Kuroda, M., Iwabuchi, K., Abe, K., and Arai, S. 1996. Soyacystatin, a novel cysteine proteinase inhibitor in soybean, is distinct in protein structure and gene organization from other cystatins of animal and plant origin. Eur. J. Biochem. 240:609-614.

24. Niebel, A., de Almeida Engler, J., Tiré, C., Engler, G., van Montagu, M., and Gheysen, G. 1993. Induction patterns of an extensin gene in tobacco upon nematode infection. Plant Cell 5:1697-1710.

25. Opperman, C. H., Taylor, C. G., and Conkling, M. A. 1994. Root-knot nematode-directed expression of a plant root-specific gene. Science 263:221-223.

26. Pernas, M., López-Solanilla, E., Sánchez-Monge, R., Salcedo, G., and Rodríguez-Palenzuela, P. 1999. Antifungal activity of a plant cystatin. Mol. Plant-Microbe Interact. 12:624-627.

27. Pernas, M., Sánchez-Monge, R., Gómez, L., and Salcedo, G. 1998. A chestnut seed cystatin differentially effective against cysteine proteinases from closely related pests. Plant Mol. Biol. 38:1235-1242.

28. Smigocki, A., Neal, J. W., McCanna, I., and Douglass, L. 1993. Cytokinin-mediated insect resistance in Nicotiana plants transformed with the ipt gene. Plant Mol. Biol. 23:325-335.
29. Snyder, G. W., Ingersoll, J. C., Smigocki, A. C., and Owens, L. D. 1999. Introduction of pathogen defense genes and a cytokinin biosynthesis gene into sugarbeet (Beta vulgaris L.) by Agrobacterium or particle bombardment. Plant Cell Rep. 18:829-834.

30. Solomon, M., Belenghi, B., Delledonne, M., Menachem, E., and Levine, A. 1999. The involvement of cysteine proteases and protease inhibitor genes in the regulation of programmed cell death in plants. Plant Cell 11:431-443.

31. Stomp, A.-M. 1992. Histochemical localization of $\beta$-glucuronidase. Pages 103-113 in: GUS Protocols. S. R. Gallagher, ed. Academic Press, San Diego.

32. Thies, J. A. 1991. NCR-138 committee (alfalfa diseases) report. Page 28 in: Twenty-second Central Alfalfa Improvement Conf., CAIC, Columbus, Ohio.

33. Tort, J., Brindley, P. J., Knox, D. P., McKerrow, J. H., and Barry, J. D. 1999. Proteinases and associated genes of parasitic helminths. Adv. Parasitol. 43:161-266.

34. Urwin, P. E., Atkinson, H. J., Waller, D. A., and McPerson, M. J. 1995. Engineered oryzacystatin-I expressed in transgenic hairy roots confers resistance to Globodera pallida. Plant J. 8:121-131.

35. Urwin, P. E., Levesley, A., McPerson, M. J., and Atkinson, H. J. 2000. Transgenic resistance to the nematode Rotylenchulus reniformis conferred by Arabidopsis thaliana plants expressing proteinase inhibitors. Mol. Breed. 6:257-264.

36. Urwin, P. E., Lilley, C. J., McPherson, M. J., and Atkinson, H. J. 1997. Characterization of two cDNAs encoding cysteine proteinases from the soybean cyst nematode. Heterodera glycines. Parasitology 114:605-613.

37. Urwin, P. E., Lilley, C. J., McPherson, M. J., and Atkinson, H. J. 1997. Resistance to both cyst and root-knot nematodes conferred by transgenic Arabidopsis expressing a modified plant cystatin. Plant J. 12:455-461.

38. Vain, P., Worland, B., Clarke, M. C., Richard, G., Beavis, M., Liu, H., Kohli, A., Leech, M., Snape, J., Christou, P., and Atkinson, H. 1998. Expression of an engineered cysteine proteinase inhibitor (Oryzacystatin-I $\triangle D 86)$ for nematode resistance in transgenic rice plants. Theor. Appl. Genet. 96:266-271.

39. Waldron, C., Wegrich, L. M., Owens-Merlo, P. A., and Walsh, T. A. 1993. Characterization of a genomic sequence coding for potato multicystatin, an eight-domain cysteine proteinase inhibitor. Plant Mol. Biol. 23:801-812.

40. Womack, J. S., Randall, J., and Kemp, J. D. 2000. Identification of a signal peptide for oryzacystatin-I. Planta 210:844-847.

41. Xu, D., McElroy, D., Thornburg, R. W., and Wu, R. 1993. Systemic induction of a potato pin 2 promoter by wounding, methyl jasmonate, and abscisic acid in transgenic rice plants. Plant Mol. Biol. 22:573-588. 